\title{
Changes in enforcement styles among environmental enforcement officials in China
}

\section{Carlos Wing-Hung Lo}

Department of Management and Marketing, The Hong Kong Polytechnic University, Hung Hom, Kowloon, Hong Kong; e-mail: mscarlos@polyu.edu.hk

\section{Gerald E Fryxell}

Department of Management, China Europe International Business School (CEIBS),

699 Hongfeng Road, Pudong 201206, Shanghai, PRC; e-mail: fryxell@ceibs.edu

\section{Benjamin Van Rooij}

School of Law, Amsterdam University, Oudemanhuispoort 4-6, 1012 CN Amsterdam,

The Netherlands; e-mail: b.vanrooij@uva.nl

Received 14 November 2008; in revised form 4 February 2009

\begin{abstract}
This study examines changes in enforcement styles among environmental enforcement officials in the context of China's rapidly changing institutional environments, using panel data collected in Guangzhou in 2000 and 2006. Altogether, five enforcement style elements were examined-accommodation, prioritization, educational, formalism, and coercion. It was found that in 2006 respondents reported greater reliance on education, formalism, and coercion than in 2000. During the same period 2000-06, no significant changes were found for the enforcement styles of accommodation and prioritization or in the respondents' perceptions of their organization's enforcement effectiveness. From regression models in which enforcement styles were used to predict perceived organizational enforcement effectiveness, it was observed that the coefficient for formalism had changed substantially over this period, from being significantly negative to significantly positive, which may be evidence of a general shift from 'rule by man' to 'rule by law' in China. This study has benefited from the concept of regulatory enforcement style elements, as it allows for an empirical understanding of regulatory enforcement beyond the common and normative dichotomy of deterrence versus cooperation.
\end{abstract}

\section{Introduction}

In the last three decades, China has adopted a legalistic approach to environmental protection and pollution control, trying to curb the negative side effects of its tremendous economic growth. It has introduced and continually improved a system of environmental laws and regulations at both the national and the local levels (Alford and Liebman, 2001; Palmer, 1998; Van Rooij, 2006). During this time China has gradually established and strengthened a structure of national and local state institutions tasked to implement and enforce these environmental regulations (Jahiel, 1998; Ma and Ortolano, 2000; Sinkule and Ortolano, 1995).

The enforcement of pollution laws in China is one of the best-documented cases of regulatory enforcement in a developmental setting, and is important for those seeking to expand existing regulatory theory beyond its current Western confines. Over the years a remarkable body of empirical work has emerged about the enforcement of pollution laws in China. This body of work is varied, being comprised of qualitative case studies of local enforcement practices (eg Lo and Tang, 2006; Ma and Ortolano, 2000; Sinkule and Ortolano, 1995; Swanson et al, 2001; Tilt, 2007; Van Rooij, 2006), statistical analyses of surveys amongst enforcement agents (eg Lo and Fryxell, 2003; 2005; Lo et al, 2006; Tang et al, 2003), and economic and econometric model-based analysis of governmental enforcement and pollution data (eg Dasgupta and Wheeler, 1997; Wang and Wheeler 2000; Wang et al, 2003). When combined, these studies provide a comprehensive view of how enforcement is organized, what positive and 
negative factors influence it, and how effective it is in influencing compliance and pollution control. They also provide different units of analysis of enforcement, including national governance arrangements and their effect on central-local arrangements, enforcement bureau institutional settings, and the perceptions of individual agents.

There is, however, an important lack in the literature on Chinese pollution enforcement: there are no serious or organized studies on how enforcement practices at the local level may be changing over time and how such changes are influenced by wider institutional transformations - an important topic of regulatory enforcement in pollution control within a rapidly developing transitional political economy. Most studies paint a static picture of law-enforcement officials adopting a conciliatory, informal, and nonstringent approach, using the discretion they have while maintaining close ties to regulated enterprises and the government institutions which own and protect them (eg Jahiel, 1997; Ma and Ortolano, 2000; Sinkule and Ortolano, 1995). It is argued that enforcement is lax and informal because local governments have persistently undermined the enforcement of pollution control by their local Environmental Protection Bureaus (EPBs) in order to protect local economic interests (eg Jahiel, 1997; 1998; Ma and Ortolano, 2000; Sinkule and Ortolano, 1995; Swanson et al, 2001; Tang et al, 1997; 2003; Van Rooij, 2006; Zhang, 2002).

Such studies further suggest that EPBs lack authority, administrative rank ('jibie'), and financial and human resources (Chan et al, 1993; Jahiel, 1997, 1998; Ma and Ortolano, 2000; Sinkule and Ortolano, 1995; Tang et al, 1997; Tilt, 2007; Van Rooij, 2003; 2006) and conclude that EPBs suffer from weak internal management processes (Van Rooij, 2003; 2006) and risk-averse enforcement agents who are afraid to upset powerful regulated actors or other government officials (Chan et al, 1995; Ma and Ortolano, 2000; Van Rooij, 2006). These problems are only exacerbated when EPBs are not supported by local communities through complaints, collective action, media involvement, or general support (Dasgupta et al, 2000; Lo and Fryxell, 2005; Lo and Leung, 2000; Wang and Wheeler, 2000; Warwick and Ortolano, 2007); or when they face powerful enterprises which try their best to undermine enforcement action (Van Rooij, 2006) and with whom they desire to maintain a good relationship (Ma and Ortolano, 2000). The static nature of the study of pollution enforcement in China is understandable. Obtaining good data continues to be difficult and few scholars are able to do so over a sufficient period of time to understand change.

Although understandable, the lack of longitudinal research is problematic-especially in hypergrowth fast-changing countries such as China. The institutional developments of the last decade in China force us to question whether the existing picture of purportedly informal and weak pollution enforcement at the street level is still correct. Indeed, since 1996 there has been mounting central government commitment to pollution control as evidenced by increases in governmental expenditures on environmental protection (Ecological Environment and Protection, 2001; OECD, 2007), an elevation in the status of its national environmental watchdog (Lo and Leung, 2000), amendments favoring stricter and stronger environmental laws (Alford and Liebman, 2001; Van Rooij, 2006), organization of pollution law enforcement campaigns (Economy, 2004; OECD, 2007; Van Rooij, 2002; 2006), and the institution of an environmental performance system for local governments (Lo and Tang, 2006).

At the same time, social pressures against pollution have become a stronger force, with rising environmental awareness and a greater, though selective, tolerance of nongovernmental organizations (NGOs) by the authorities (Ho, 2001; Ho and Edmonds, 2008; Stalley and Yang, 2006; Yang, 2005). Citizen complaints about pollution have emerged to become an important influence on EPB enforcement work, increasing by nearly 150\% between 2000 and 2006 (State Environmental Protection Administration, 
2000 -2006). State-enterprise relations have also improved as the economy has been privatized and state-owned and collectively owned enterprises restructured (Lo and Tang, 2006).

Since the 1990s Chinese bureaucracy has been somewhat more professionalized following the introduction of the merit-based civil service system (Burns, 1999) and the resultant appointment of specialized, educated staff in the EPBs (Van Rooij, 2006). The strengthening of the legal system (Peerenboom, 2002) and China's entry into the WTO in 2000 have also pressured environmental agencies and their officials to be more formal and consistent in enforcement (Ferris and Zhang 2002; Lo and Chung, 2003).

In addition, some local governments, who have traditionally been blamed for the weak enforcement of environmental laws, have shown relatively greater commitment to the environment. For example, some local governments have started to invest more in environmental protection, providing stronger support for local EPBs (Lo and Fryxell, 2005; Lo et al, 2006), and introducing more pro-environment language into their general policy plans. In some cases, local governments have even introduced local environmental regulations that are more stringent than the national ones in the hope of obtaining various 'green credentials'. Whereas such 'State Environmental Protection Model Cities' designations have traditionally gone to relatively low-industry cities (eg Zhuhai and Xiamen), some are now being granted to pro-growth industrial centers (eg Dalian, Guangzhou, and Wuhan) (Lo et al, 2006).

It would be reasonable to expect that such institutional developments have affected street-level pollution law enforcement. However, the existing literature has yet to capture what changes may have occurred. To address this gap in the literature, in this paper we provide a longitudinal study of pollution law enforcement in China. We seek to answer two important questions: (1) how are regulatory enforcement styles changing in China and (2) how have enforcement agents' perceptions about the effectiveness of different enforcement styles changed? These questions will be addressed using survey data from environmental enforcement officials in Guangzhou collected in 2000 and 2006. This period coincides with the implementation of the 10th Five-Year Plan during which many of China's aforementioned larger social, economic, legal, and administrative developments occurred. Guangzhou city, although obviously not representative of China, is ideally suited for a study on enforcement change in this period because it is one of the major urban and industrial centers where the local government has shown a relatively strong commitment to environmental protection (Lo et al, 2006) and where many of the aforementioned national institutional developments have been influential.

Compared with other large cities in China, the Guangzhou municipal government is relatively more advanced in terms of its environmental protection measures, having established a comprehensive set of local environmental protection regulations and organizations (Lo, 1994; Lo and Leung, 2000). Among the thirty-seven major cities that participated in an annual assessment conducted by the Ministry of Environmental Protection (until 2008, the State Environmental Protection Administration), Guangzhou was ranked in the top ten every year from 1988 to 1994 and was given a coveted award in 1995 for its environmental protection work. However, despite regular national recognition, the city has, in fact, achieved very mixed results in its environmental regulation efforts. Although, the pace of environmental degradation may have slowed, many environmental indicators remain far below minimum national standards (Lo and Fryxell, 2005). In many ways, Guangzhou is typical of most major cities in the coastal areas that have been dominated by a strong pro-growth orientation (eg Beijing, Shanghai, Tianjin, and Nanjing), but which have kept on rethinking their policies and enforcement strategies in the face of serious environmental degradation within a rapidly changing regulatory setting. 
This longitudinal study builds on our earlier study of enforcement styles among enforcement officials in the three Chinese cities of Chengdu, Dalian, and Guangzhou, conducted in 2000 (Lo and Fryxell, 2003; Tang et al, 2003). It uses the same set of questions to extend the analysis of cross-jurisdiction variation in enforcement styles to that of temporal changes. This allows for a direct comparison of changes in enforcement in a particular geographical setting - something which is impossible from current qualitative data derived from multiple settings and which have used different research questions and approaches. In this process, we have refined the original conceptual formulation of enforcement styles to capture more accurately the differences in the two periods. These two elements combine so that this study advances the boundary of current enforcement research.

\section{Conceptual development}

In order to capture changes in regulatory enforcement more accurately, this study uses the concept of 'enforcement style elements'. This term is a refinement of the original 'enforcement style concept', made popular by the regulatory enforcement literature.

'Enforcement style' can be defined as the general approach assumed by an enforcement official in the course of performing regulatory duties (see Bardach and Kagan, 1982; Hawkins, 1984; Reiss, 1984). Originally, two major styles were discerned: 'deterrence' and 'cooperation' (also sometimes called compliance) (Kagan, 1994; Reiss, 1984). Proponents of deterrence contended that only the consistent and rigid use of relatively stringent sanctions can deter regulated actors from violating the law (Becker, 1968; Gunningham, 1987; Kagan, 1994). Cooperation adherents, in contrast, argued that sustained compliance is fostered when the agent and the regulated actor understand each other better and work together towards compliance. This suggests a role for agent discretion and the use of educational persuasive methods rather than sanctions (Kagan and Scholz, 1984; Reiss, 1984). Early research largely followed this dichotomy. In reality, however, approaches to enforcement are far more subtle, with enforcement styles being mixed and multifaceted; a closer inspection reveals several underlying elements which combine into enforcement styles (Ayres and Braithwaite, 1992; Kagan, 1994; 2000; Kagan and Scholz, 1984; May and Winter, 1999).

Our analysis of the regulatory enforcement literature yields five major enforcement style elements:

(1) Formalism. This enforcement style element refers to adherence to rather rigid legal requirements and may be expressed through firm implementation deadlines, specific environmental standards linked to clear penalties, and a reluctance to consider mitigating circumstances (eg cost-benefit considerations) (Braithwaite et al, 1987; Gormley, 1998; Hawkins, 1984; Kagan, 1994).

(2) Coercion. This is an enforcement style element which stresses the force of law, and is manifested in a strong propensity to impose - or signal the imposition of - sanctions for non-compliance (Hawkins, 1984; Richardson et al, 1983).

(3) Educational. This enforcement style element emphasizes the communicative function of the law, seeing the potential for using education of regulated enterprises and the general public as a means to inculcate more environmentally responsible behavior (Kagan and Scholz, 1984; May and Winter, 1999; Scholz and Gray, 1997).

(4) Prioritization. This element indicates pragmatic enforcement that tries to get the most effective result within the given contextual restraints and while considering the circumstances at hand. Such enforcement requires a prioritization of regulated actors and violations which informs the use of scarce enforcement resources (Bardach and Kagan, 1982; Gray and Scholz, 1991; May and Winter, 1999). 
(5) Accommodation. This emphasizes the reconciliation of the demands of key stakeholders in regulatory enforcement. In doing so, enforcement agents consider the opinions of, for instance, political leaders and their constituencies (Frank and Lombness, 1988; Hutter, 1989; Scholz et al, 1991; Wood, 1988; Wood and Waterman, 1991).

In their purest form none of these style elements is likely to be effective on its own as all style elements have their advantages and limitations. Formalism, for example, allows for reducing discretionary administration in the interests of preventing corruption, enhancing deterrence, promoting equity, or empowering the public (Bardach and Kagan, 1982; Gunningham et al, 1992; Langbein, 2002), but can easily become counterproductive to the extent that it arouses hostility or otherwise frustrates cooperation (eg May and Winter, 1999). Prioritization offers the advantage of maximizing the effect of scarce enforcement resources (Bardach and Kagan, 1982; Gray and Scholz, 1991; May and Winter, 1999). However, it is difficult to establish the right priorities in advance (May and Winter, 1999), and failure to do so can lead to goal displacement as set priorities become more important than regulating the largest risks. Hence, effective enforcement styles are combinations of these elements, rather than pure forms of one or even two elements (Ayres and Braithwaite, 1992; Kagan and Scholz, 1984; May and Winter, 1999). Therefore, enforcement style elements are neither mutually exclusive nor independent.

This longitudinal study of pollution enforcement in China uses the refined construct of the five enforcement style elements to understand how enforcement has changed between 2000 and 2006. We seek to understand the changes in the composition of the five elements. In addition, we seek to understand how Chinese enforcement agents perceive the organizational effectiveness of these elements, and how this perception has changed during this period. We follow the regulatory literature in conceptualizing enforcement effectiveness in terms of obtaining compliance and achieving the intentions of a regulation or set of regulations (eg May and Wood, 2003; Scholz, 1984).

\section{Methodology}

The data for this study come from surveys conducted among environmental officials in the Guangzhou Environmental Protection Bureau (GEPB). The GEPB is responsible for enforcement of the environmental regulations of Guangzhou municipality, the capital city of Guangdong Province, located in the Pearl River Delta region.

With an area of $7434.6 \mathrm{~km}^{2}$ and a population of over 7.5 million, Guangzhou municipality is a reasonably good setting for this study of changes in regulatory enforcement style in pollution control. Economically, it has been among the fastest developing local economies in China, with a GDP that has seen a phenomenal increase from around 5 billion RMB in the early 1980s to more than 206 billion RMB in 1999, and then to 623 billion RMB in 2006. Environmentally, Guangzhou has experienced serious degradation of its air, water, and other environmental resources resulting from its rapid economic growth in the last two decades. Politically, senior municipal leaders have increasingly incorporated environmental protection as a major component of the city's development strategy, with a strong desire to give the city a green image. Socially, Guangzhou citizens have become more critical and less tolerant of industrial pollution as their society is in the fast lane to economic affluence, leading to the emergence of a more environmentally aware society (Lo and Leung, 2000). All these institutional developments have created tremendous pressure on the GEPB to tighten regulatory control over polluting enterprises. To strengthen the empirical basis of this study, we supplemented the survey findings with the analysis of interviews with eleven out of the twelve enforcement teams of the GEPB. 


\section{Data collection}

The survey was administered in the years 2000 and 2006-each time with the endorsement and support of the GEPB, which greatly facilitated its administration and enhanced response rates. Prior to each round of data collection a briefing session was held with representatives at each field office. These representatives, in turn, helped distribute the questionnaires to officials within their units, collected completed questionnaires, and returned them. The respondents were all 'street-level' officials within the GEPB who were either currently or formerly responsible for carrying out enforcement duties over industrial enterprises in Guangzhou. Altogether 202 usable responses were received from a total of 250 questionnaires distributed in 2000, and 154 of 220 were received in 2006-response rates of $81 \%$ and $70 \%$, respectively. Because of the low turnover in enforcement officials $(\sim 5 \% /$ year $)$, the samples are reasonably comparable. Indeed, because over $70 \%$ of the respondents had over six years of job tenure, a large number of the respondents were working for the agency during both data-collection periods. As for the interviews with enforcement teams, these were conducted between August 2006 and July 2007. In most of these interviews there were at least one leading official (team or deputy team leader) and two or three enforcement officials from the enforcement team. These semistructured interviews were arranged by the Guangzhou Research Institute of Environmental Science, the research arm of the GEPB, and questions focused on seven aspects of regulatory control: major tasks of enforcement, regulatory strategies, enforcement difficulties, experiences in enforcement, sources of enforcement pressure, possible improvement, and government and public expectation.

\section{Measurement}

Control variables. Three variables were used to control for individual variation among the enforcement officials:

(1) gender - the respondents' gender was dummy coded (ie ' 0 ' for males and ' 1 ' for females);

(2) Age - the respondents' age was measured directly in years at the time of the survey; and

(3) Job tenure - the number of years the respondent had worked as an enforcement official.

Enforcement style elements. We used a total of seventeen items to measure the enforcement style elements derived earlier in the paper from the literature. Each item posed a statement about approaches to enforcement, on which the enforcement officials indicated how strongly they incorporated that approach in their enforcement actions on a five-point, Likert-type scale. Prior to forming the scales, a principal components analysis was conducted. As anticipated, five components were extracted-each with an eigenvalue greater than 1.0. Taken together these components accounted for $60.2 \%$ of the variance among the seventeen items. This analysis is reported in table 1 , which also gives the specific wording for each item.

Scales were then formed for each enforcement style element by taking an average for the items under each heading in table 1 . The reliability statistics for these scales were as follows: formalism, 4 items $-\alpha=0.65$; coercion, 2 items $-\alpha=0.54$; educational, 2 items $-\alpha=0.88$; prioritization, 5 items $-\alpha=0.66$; and accommodation, 4 items$\alpha=0.85$. The reliability for the coercive style element, in particular, was substantially lower than we would have hoped for. Nevertheless, rather than discard it we decided to retain it simply because it is an intuitively appealing style element and, even if the items are somewhat internally inconsistent, it may be interesting to track its changes. Some additional caution, however, is warranted in any interpretations involving this particular enforcement style element. 
Table 1. Principle component analysis of enforcement-style items (combined samples).

\begin{tabular}{|c|c|c|c|c|c|}
\hline \multirow[t]{2}{*}{ Component/item content } & \multicolumn{5}{|c|}{ Component ${ }^{\mathrm{a}}$} \\
\hline & 1 & 2 & 3 & 4 & 5 \\
\hline \multicolumn{6}{|l|}{ Formalism } \\
\hline 1. I emphasize strict law enforcement rather than consultation & -0.037 & -0.020 & 0.647 & 0.146 & 0.247 \\
\hline 2. I emphasize legal requirements rather than personal attitudes in enforcement & -0.057 & 0.053 & 0.757 & -0.078 & -0.045 \\
\hline 3. I emphasize legal requirements rather than outcomes in enforcement & -0.005 & -0.007 & 0.606 & 0.150 & 0.380 \\
\hline 4. I emphasize consistency rather than flexibility in enforcement & -0.047 & -0.076 & 0.797 & -0.019 & -0.114 \\
\hline \multicolumn{6}{|l|}{ Coercion } \\
\hline 5. There is more suspicion than trust between myself and the organizations I inspect & 0.083 & 0.013 & 0.139 & -0.032 & 0.763 \\
\hline 6. I adopt a strict and threatening attitude rather than penalty avoidance in enforcement & 0.065 & 0.085 & 0.014 & -0.057 & 0.818 \\
\hline \multicolumn{6}{|l|}{ Educational } \\
\hline 7. I emphasize educating the public in seeking enforcement & -0.022 & 0.039 & 0.021 & 0.941 & -0.010 \\
\hline 8. I emphasize educating business in seeking enforcement & 0.006 & 0.077 & 0.090 & 0.933 & -0.066 \\
\hline \multicolumn{6}{|l|}{ Prioritization } \\
\hline 9. I have enough discretion to handle each case flexibly & 0.163 & 0.602 & -0.076 & -0.032 & 0.170 \\
\hline 10. I handle each case individually on a case-by-case basis with no single standard approach & 0.191 & 0.600 & 0.002 & -0.066 & -0.016 \\
\hline 11. The ability (of a business) to pay is an important factor I consider in each case & 0.080 & 0.751 & -0.017 & 0.137 & -0.046 \\
\hline 12. The cooperative attitude of a business is an important factor I consider in each case & 0.167 & 0.646 & -0.044 & 0.187 & 0.112 \\
\hline 13. The kind of pollution is an important factor I consider in each case & 0.150 & 0.592 & 0.069 & -0.040 & -0.051 \\
\hline \multicolumn{6}{|l|}{ Accommodation } \\
\hline 14. My colleagues have an important influence on my working standards & 0.785 & 0.233 & -0.025 & -0.058 & 0.012 \\
\hline 15. My subordinates have an important influence on my working standards & 0.814 & 0.229 & 0.042 & -0.004 & 0.023 \\
\hline 16. Other departments have an important influence on my working standards & 0.810 & 0.245 & -0.109 & 0.034 & 0.079 \\
\hline 17. Businesses have an important influence on my working standards. & 0.834 & 0.115 & -0.083 & 0.015 & 0.093 \\
\hline
\end{tabular}


Perceived enforcement effectiveness. In this study we are interested in the enforcement officials' perceptions of the effectiveness of their organization in enforcement (ie, at the unit and agency levels), rather than in them providing a self-assessment of their own work. The rationale for this is twofold: to distance this assessment from biases or unease associated what would effectively be a performance appraisal; but, more importantly, to link enforcement-style elements as shaped by the broader institutional environment to the enforcement effectiveness of the respondent's unit and agency. Accordingly, we used respondents' self-reports at two levels (unit and agency) to the following questions: (1) "Overall, my unit is effective in enforcing regulations"; and "Overall, my agency is effective in the enforcement of regulations". As before, each of these items was presented in a five-point Likert-type format. The resulting two-item scale demonstrated a high level of internal consistency $(\alpha=0.841)$.

\section{Analysis}

Descriptive statistics and tests of differences in means for the 2000 and 2006 results were performed using SPSS. The regression models predicting organizational enforcement effectiveness, however, were estimated using AMOS 7.0, which provides maximum-likelihood estimates and more easily permits statistical tests of differences in the coefficients in our two samples (a $\chi^{2}$-test).

\section{Results}

The means and standard deviations for the control variables and enforcement style elements (by item and as a two-item index) for the 2000 and 2006 samples are given in table 2. As shown in this table, the means for the control variables indicate that the typical respondent was male (roughly two thirds of each sample), 37 years of age, and had just over ten years' experience working as an enforcement official. The two samples

Table 2. Comparison of controls, enforcement styles, and organizational enforcement effectiveness (2000 and 2006 samples).

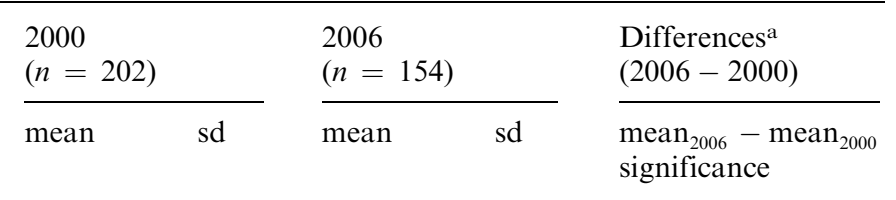

Control variables

Gender

$(0=$ male; 1 = female $)$

Age (years)

Job tenure (years)

$\begin{array}{lllll}0.39 & 0.488 & 0.33 & 0.471 & 0.06\end{array}$

$\begin{array}{lllll}37.4 & 9.43 & 37.5 & 7.86 & 0.01 \\ 10.06 & 6.65 & 10.39 & 6.58 & 0.33\end{array}$

Indices of enforcement styles

External influence

$(\alpha=0.823)$

Prioritization $(\alpha=0.659)$

Educational $(\alpha=0.884)$

Formalism $(\alpha=0.670)$

Coercion $(\alpha=0.542)$

10.06

6.65

10.39

6.58

0.33

$2.49(4)^{\mathrm{a}} \quad 0.594 \quad 2.57(5)^{\mathrm{b}} \quad 0.604 \quad 0.08$

$2.74(3) \quad 0.586 \quad 2.85(3) \quad 0.630 \quad 0.11$

$3.41(1) \quad 0.919$

3.59 (1) $\quad 0.720$

$0.18^{*}$

$\begin{array}{lllll}2.99(2) & 0.681 & 3.19(2) & 0.582 & \mathbf{0 . 2 0}\end{array}$

Perceptions of organizational enforcement effectiveness

$\begin{array}{llllll}\text { Enforcement effectiveness } & 3.97 & 0.467 & 3.93 & 0.467 & -0.04\end{array}$

(2-item scale; $\alpha=0.841$ )

Note: sd, standard deviation

${ }^{a}$ Independent samples $t$-tests (2-tailed); $* p \leqslant 0.05 ; * * p<0.01$.

b Rank ordered from highest to lowest scores. 
appear to be similar in terms of these demographics, with no significant differences between the 2000 and 2006 samples (a gender shift toward males is indicated at the 0.10 level).

Among the enforcement style elements, the greatest emphasis in both samples appears to have been placed on the educational style element (based on a rank ordering of the means from highest to lowest). Perhaps this should not be too surprising given the fairly low base of understanding among the business community regarding the relevance of environmental performance, the economic priorities of many local government officials, and the low power base of most EPB officials. At the opposite end, whereas coercion was easily the least emphasized style element in the 2000 sample (mean $=2.29$ ), the accommodation style element was the least favored in 2006 (mean $=2.57$, just under 2.59 for the coercion style element). Whereas all five style elements had higher means in 2006, only educational, formalism, and coercion style elements had statistically significant increases $(p<0.05)$. This provides support for our assumption that enforcement style elements would have changed significantly since the year 2000 .

Finally, we would note that the means of the perceived organizational enforcement effectiveness scale appear unchanged. Consequently, it appears that, regardless of the increased pressures for better enforcement and a demonstrable shift in enforcement styles, these self-reports of enforcement effectiveness do not indicate that the frequency of regulatory compliance has improved during this period. Although caution must be used when interpreting 'nonfindings', this result is certainly intriguing and warrants further investigation into why a push for better enforcement in Guangzhou, along with additional resources, should have accomplished so little, at least in the eyes of these front-line respondents.

Table 3 provides Pearson correlations among the control items and scales for enforcement style elements and perception of organizational enforcement effectiveness for both samples (those for the 2000 sample are below and to the left of the diagonal; those for the 2006 sample are above and to the right of it). High values are observed between some of the enforcement style elements. In particular, in 2006 the accommodation and prioritization style elements had a strong, positive relationship $\left(r_{x y}=0.478\right)$, perhaps because these two styles both emphasize flexibility. Formalism and coercion also had a fairly strong, positive relationship in $2006\left(r_{x y}=0.413\right)$. It is likely that, from time to time, a formalistic style may require a measure of confrontation when pushing for doing things a certain way. Interestingly, these relationships are considerably weaker in the 2000 sample $\left(r_{x y}=0.374\right.$ for accommodation and prioritization, and only $r_{x y}=0.011$ for coercion and formalism). The linking of coercion and formalism in 2006 is especially illuminating and may reflect some aggressiveness on the part of agency officials in pushing for formalism during this period.

In order to analyze the second question-regarding how enforcement agents perceive the organizational effectiveness of the enforcement elements and how this perception has changed between 2000 and 2006-we estimated regression models in which each style element served as a predictor of perceived organizational enforcement effectiveness along with the control variables. These estimates are reported in table 4 .

As is evident in table 4, the pattern of significant main effects is substantially different in the two samples. For the 2000 sample, the only significant coefficient is for the educational enforcement style element $(\beta=0.146)$; in comparison, in 2006 the educational style element was replaced by formalism as the only significant, positive effect $(\beta=0.200)$. Also in 2006, the coercion and accommodation style elements have significant negative coefficients $\left(\beta_{s}=0.127\right.$ and $\beta=-0.153$, respectively), indicating that agents may have come to see them as counterproductive. In simpler terms, in 2000 
Table 3. Pearson correlations of control variables, indices of enforcement style elements, and index of organizational enforcement effectiveness (2000 and 2006 samples).

\begin{tabular}{|c|c|c|c|c|c|}
\hline & 1 & 2 & 3 & 4 & 5 \\
\hline Gender & & -0.017 & 0.011 & -0.016 & 0.053 \\
\hline Age & -0.051 & & $0.640 * * *$ & 0.012 & $-0.401 * * *$ \\
\hline Job tenure & 0.045 & $0.532 * * *$ & & 0.021 & $-0.269 * * *$ \\
\hline Accommodation & $0.191 *$ & -0.058 & -0.041 & & $0.478 * * *$ \\
\hline Prioritization & 0.118 & -0.122 & $-0.196 * *$ & $0.374 * * *$ & \\
\hline Educational & -0.041 & 0.050 & 0.044 & -0.038 & $0.156^{* *}$ \\
\hline Formalism & -0.086 & $0.272 * * *$ & $0.194 * *$ & -0.121 & 0.008 \\
\hline Coercion & 0.024 & -0.066 & -0.089 & $0.337 * * *$ & $0.157 * *$ \\
\hline \multirow{2}{*}{$\begin{array}{l}\text { Organizational } \\
\text { enforcement effectiveness }\end{array}$} & -0.013 & 0.105 & 0.133 & -0.074 & 0.054 \\
\hline & 6 & 7 & 8 & 9 & \\
\hline Gender & 0.064 & -0.036 & -0.084 & $0.169 *$ & \\
\hline Age & -0.033 & $0.158 *$ & -0.049 & $-0.246 * * *$ & \\
\hline Job tenure & 0.013 & 0.066 & $-0.183 * *$ & -0.109 & \\
\hline Accommodation & 0.035 & -0.123 & -0.052 & $-0.184^{* *}$ & \\
\hline Prioritization & -0.002 & $-0.178^{* *}$ & 0.010 & 0.035 & \\
\hline Educational & & -0.019 & -0.091 & $0.134^{*}$ & \\
\hline Formalism & 0.108 & & $0.413 * * *$ & 0.158* & \\
\hline Coercion & -0.109 & 0.011 & & -0.075 & \\
\hline Organizational & $0.318 * * *$ & -0.043 & $-0.131 *$ & & \\
\hline
\end{tabular}

enforcement effectiveness

Note. Correlations for the 2000 sample are given in the lower left portion of the table; those for the 2006 sample are in the upper right.

$* p<0.10 ; * * p<0.05 ; * * * p<0.01$.

Table 4. Regression coefficients predicting organizational enforcement effectiveness and difference tests (maximum-likelihood estimates) (2000 and 2006 samples).

$2000^{\mathrm{a}} \quad 2006^{\mathrm{a}} \quad$ Differences $(2006-2000)^{\mathrm{b}}$

Control variables

Gender

Age

Job tenure

-0.019
0.005

$\begin{array}{rr}0.151 & \mathbf{0 . 1 7 0} \\ -\mathbf{0 . 0 1 4} & -\mathbf{0 . 0 1 9} \\ 0.003 & -0.004\end{array}$

Main effects

Formalism

Coercion

0.007

0.003

$-0.004$

Educational

$-0.096$

0.200

0.296

$-0.045$

$-\mathbf{0 . 1 2 7}$

$-0.082$

Prioritization

0.146

0.079

$-0.067$

Accommodation

0.071

0.086

0.015

Model information

$R^{2}$

$-0.050$

$-0.153$

$-0.103$

$\Delta R^{2}$

$\begin{array}{ll}0.144 & 0.179 \\ 0.115 & 0.088\end{array}$

a Significant coefficients, based on $t$-test $p<0.05$, are shown in bold face.

b Significant differences in the estimates are in bold-face: based on $\chi^{2}$ different test $(1 \mathrm{df})$ $p<0.05$. 
the only style that agents saw as being effective in the attainment of enforcement at the organizational level was educational; six years later, however, educational is no longer significant, and formalism (ie rigid application of the rules) appears to have displaced it. In addition, by 2006 an emphasis on accommodation and coercion appears to be perceived as possibly undermining organizational enforcement effectiveness. Although these effects are significantly different from zero in 2006 , one should be cautious in reading too much into actual changes during this time. Statistical tests of differences in the 2000 and 2006 coefficients indicate that the only significant change among the main effects during this period was for formalism. Interestingly, among the control variables we also found significant changes in the influence of gender and age on the perception of organizational enforcement effectiveness. It appears that female enforcement agents became more inclined to view organizational enforcement effectiveness favorably over this period of time, whereas older enforcement agents became less inclined to do so. We might speculate that older enforcement agents may have been resistant to change and, as a result, somewhat more skeptical of progress in enforcement. The gender shift is certainly intriguing, but we have no obvious explanation for this.

Overall, we take these results as being consistent with a greater emphasis on the rule of law and the empowerment of the State Environmental Protection Administration (Ministry of Environmental Protection since 2008) and the EPBs over this period. The consequence of both these developments has been an increase in pressure on enforcement officials to 'deliver the goods' consistently and defensibly in terms of pollution reduction and regulatory enforcement. It is also our opinion that this is a manifestation of a larger maturation of the system and erosion of enforcement by 'guanxi' (a form of 'external influence' consisting of personal relationships guided by cultural rules based on kinship, informal authority, and/or common experiences). The shift toward coercion probably reflects a mix of downward push from agency superiors along with impatience and frustration with the regulated industries on the part of the enforcement officials themselves.

\section{Discussion}

These findings demonstrate a reasonably close linkage between regulatory environments and enforcement style elements in a dynamic context where enforcement officials presumably adjust their styles in response to the evolving institutional context. In the context of China-and especially in Guangzhou-both external pressure and support for more stringent regulatory enforcement have been growing. Nationally, the effect of this growth on enforcement is visible in data from China's annual statistical reports on the environment (see table 5). These data show a $30 \%$ increase in the number of administrative enforcement cases during the period from 2001 to 2006. Meanwhile, the same data show that the average fine per case has increased substantially from 3307 RMB in 2001 to 10427 RMB in 2006-or an increase of $208 \%$. This indicates not only that there are more frequent enforcement actions, but also that each individual action is more stringent. Moreover, this has happened at a time when the number of written environmental complaints (Xinfang) increased by $67 \%$. Thus, increasing external pressure on EPBs for greater enforcement effectiveness is clearly evident (State Environmental Protection Administration, 2001 - 2006). Guangzhou has followed a similar pattern, as shown by data obtained from the GEPB. The number of administrative enforcement cases grew from 256 in 1998 to 1547 in 2006, the average fines were $5207 \mathrm{RMB}$ in 1998 and $45639 \mathrm{RMB}$ in 2006, and the number of written complaints about pollution increased from 5300 in 1999 to 20192 in 2006. Assuming that pressure for enforcement is matched with support, our surveys also confirm this shift as they 
Table 5. China national environmental enforcement statistics 1998-2006.

\begin{tabular}{llll}
\hline & $\begin{array}{l}\text { Administrative } \\
\text { enforcement cases }\end{array}$ & $\begin{array}{l}\text { Average fine } \\
\text { per case (RMB) }\end{array}$ & $\begin{array}{l}\text { Written citizen complaints } \\
\text { about pollution }\end{array}$ \\
\hline 1998 & 39754 & na & na \\
1999 & 53101 & na & na \\
2000 & 55209 & na & 369712 \\
2001 & 71089 & 3377 & 435420 \\
2002 & 100103 & 3017 & 525988 \\
2003 & 92818 & 3546 & 595852 \\
2004 & 80079 & 5747 & 608245 \\
2005 & 93265 & 6868 & 616122 \\
2006 & 92404 & 10427 &
\end{tabular}

included a series of questions asking enforcement officials about their perceptions regarding support for enforcement from various societal sectors (ie, the public, mass media, business, and social environmental organizations). Except for business, all showed a substantial and statistically significant shift in the level of support for enforcement.

Indeed, in the period between 2000 and 2006 in Guangzhou, there was even a measure of urgency about prioritizing regulatory enforcement as the municipal government embraced the designation of 'green model city' as a priority in its 10th Five-Year Plan (Pearl River Environment News 2006). This led to the establishment of the Achieving Model City Target Responsibility System at all levels of the municipal government. Of particular interest to this study was that enforcement officials were advised to modify their enforcement styles in three ways: (1) to be more assertive in collecting pollution discharge fees; (2) to become more strict with polluting enterprises (ie, regardless of their 'connections'); and (3) to enforce the legal requirements of two specific policies - the 'three synchronizations' and the 'imposition of deadlines on enterprises to control and reduce their pollution levels' (Pearl River Environment News 2006). Taken together, this would appear to be a rallying cry for the styles of formalism and coercion. This call to action seems to have also been picked up by the media and the public, and has led to more frequent complaints-sometimes even when there has been no violation of the law. Such public pressure had become a major source of influence on EPB agents by 2006, according to most agents interviewed in depth in the eleven Guangzhou district EPBs.

Overall, this system has led to somewhat tougher punishment for violations of pollution regulations and an increased allocation of financial resources (to an average of $2 \%$ of GPD per year during this period). In addition, at about this time the Guangzhou EPB also began periodically to publicize habitual violators (Pearl River Environment News 2006). The stress on a more legal approach was further underscored when the Chief of the EPB symbolically appointed an environmental official who was a law graduate to head the enforcement team. With this legalistic mandate and external support in the task environment, enforcement officials were encouraged to shift their enforcement style elements away from prioritization and accommodation and toward formalism and coercion.

Our findings demonstrate that by 2006 regulatory enforcement officials in the Guangzhou EPB were found to be placing relatively greater emphasis on the educational, formalism, and coercion style elements. The greater emphasis on the educational style does not appear to fit with the background given above, but continues to play a role due to the relatively nascent awareness in China that environmental protection 
is a legitimate business issue - given the relatively free hand most businesses had had in pursuing profits. Thus, some additional 'evangelism' on the part of enforcement officials may have been expected in order to increase enterprise managements' willingness to comply during this period. The more significant shifts, however, were found in style elements associated with applying the law more literally (ie, formalism) and with more 'teeth' (ie, coercion). These findings are further supported by our qualitative in-depth interviews with enforcement officials of the eleven Guangzhou district EPBs. Many officials noted that enforcement had become tougher, with more emphasis on stricter punishment, and enforcement was also more 'by the book'.

Although educational and formalism would be relatively easy to associate with professionalism and maturity, one would not normally associate coercion with such virtues. However, coercion need not have much of the negative baggage often associated with the word (eg, duress or threats of physical harm). For example, in this context it might be construed more as a signal that the official (and agency) 'means business', with an emphasis on credible negative consequences for continued violations. Indeed, if linked to formalism (consistency), then it could be construed as a frequent (and probably necessary) reminder of the negative consequences of noncompliance. This would certainly fit the change in the regulatory climate in Guangzhou from 2000 to 2006 as described above. At the same time, there are also some signs of stability in our data. For example, no significant increases were found for the accommodation and prioritization dimensions, and enforcement preferences among the five enforcement style elements (ie, the rank ordering) appear to have remained roughly the same in the two periods. The only change in these preferences was that the accommodation style element was replaced by the coercion approach as the least favored in 2006. As for prioritization, this is probably because the context in which it developed has not changed much - the increase in the resource support has not been in proportion to the rapid expansion of the scale and scope of regulatory duties. During the interviews enforcement agents indicated that they use prioritization as a way to manage scarce enforcement resources when trying to regulate a large number of polluting enterprises - a basic challenge that existed both in 2000 and in 2006.

These findings also support the view that regulatory officials usually adopt a combination of enforcement style elements in performing regulatory control. Given the increasing pressure to get demonstrable results (ie, reduced pollution, more violations cited), the major objective for enforcement officials was to arrive at the best mix of style elements to perform their job-as they best understood it in terms of enforcement effectiveness. Hence they have included more formalism, coercion, and educational into this mix - formalism and coercion for better enforcement (at least in their minds) and educational to improve compliance.

With respect to the issue of outcomes, this study also examined likely shifts in the relationship of various styles with enforcement officials' perceptions of organizational enforcement effectiveness (ie, at the unit and agency levels). It was found that the pattern of significant relationships was quite different in 2000 and 2006. Specifically, in 2000 only an educational enforcement style element was positively associated with organizational effectiveness. In comparison, only formalism was positive in 2006, while accommodation and coercion were found to have negative direct effects. However, a statistical test of these differences revealed that the main shift was for the formalism enforcement style. This would permit the broad general conclusion that formalism has emerged as being deemed to have a much more positive influence on organizational enforcement effectiveness compared with the situation before the 10th Five-Year Plan. Evidently, formalism now fits better with the institutional context of regulatory enforcement in China, with the emerging preference for tightening up pollution control 
through more stringent enforcement in order to achieve quick and visible results of cleaning up the deteriorating industrial pollution. This would appear to provide support for institutional theory overall, in that it seems that we are seeing a shift in response to contextual changes. Formalism is better suited than other enforcement style elements to getting results in the current context.

Having said this, it is noteworthy that no significant change was found in agent responses about how they perceived organizational enforcement effectiveness. Certainly, one might have hoped for some indication that enforcement effectiveness had improved, especially insofar as the agency seems to have pushed very hard for it. So, what might have happened? First, it is entirely possible that the perceived benefits of formalism were offset by enforcement style elements deemed to be less productive. Indeed, this study found negative perceptions about the effects of coercion and accommodation, with the coersion increasing in emphasis and accommodation maintaining its presence. A second explanation could be that enforcement effectiveness actually did improve somewhat during this period, but that this was not picked up by our perceptional measure. Some tangible evidence of improved enforcement effectiveness might include the fact that by 2006 Guangzhou had fulfilled all the major requirements to achieve recognition as an "Environmental Model City" (Pearl River Environment News 2006), had closed or relocated 140 large polluting factories (Pearl River Environment News 2006) and been successful in criminally prosecuting two firms. On the other hand, it is possible that a perceptual evaluation of organizational enforcement effectiveness may have been based on a more ambitious benchmark in 2006 than in 2000. This 'moving target effect' on the perception of enforcement effectiveness could be quite strong in the regulatory context of a fast-growing economy where people's expectations of environmental quality keep on rising. A third possibility would recognize that organizational enforcement effectiveness is a two-way street. Not only must enforcement officials enforce the regulations effectively, but the regulated have to be at least somewhat predisposed to comply. Given the numerous anecdotes regarding the creative ways in which companies try to beat the system (eg turning on pollution abatement devices only when 'tipped off', or storing and then releasing pollutants in the middle of the night), it is possible that better enforcement was offset by perception of equally creative noncompliance.

\section{Limitations}

Some limitations of this study warrant comment. First, our use of self-reported measures of organizational enforcement effectiveness may have been subject to certain biases (single-method and social desirability influences, in particular). However, not only would it have been difficult to obtain data regarding the actual extent to which the regulations are flaunted [ie, enterprises are not required to report or publish actual emissions, as is the case (with toxic release inventory) reporting in the United States], but objective measures would have had imperfections of their own. For example, the number of citations issued by enforcement officials (assuming we could even have obtained this more sensitive data), although correlated with the number of violations found, could easily be confounded with our measures of enforcement style (eg, a formalistic style would lead to more citations than would an educational style). Second, some of our measures of enforcement style elements suffered from imprecision. Two measures, those for formalism and prioritization, were near the well-established heuristic of 0.7 for the $\alpha$ statistic, whereas that for coercion was conspicuously low at 0.54 . Generally, such imprecision in measurement is manifested as inflated standard errors for estimates associated with such measures; however, 
this would normally raise questions about the validity of such measures. Accordingly, caution is warranted in the interpretation of our findings associated with those measures. Third, in this study we looked at enforcement style in a single city in China-Guangzhou. Obviously, it would have improved our ability to generalize our findings if we could have systematically sampled enforcement officials from every province. Unfortunately, this was not only beyond the limits of our resources but, more importantly, beyond the limits of our contacts.

\section{Conclusion}

In this study we set out to examine two important questions: "Have regulatory enforcement styles in China changed since the advent of the 10th Five-Year Plan which provided a greener platform of development?" and "How has the enforcement agents' perception of the organizational effectiveness of different enforcement styles changed?" Using data from just before and just after the implementation of the 10th Five-Year Plan in Guangzhou - although Guangzhou is clearly not representative of all large urban areas in China, it is not unlike many in facing the challenges of rapid industrialization and severe environmental consequences from it - this study demonstrates a clear linkage of changes between institutional environments and enforcement stylethe implication being one of 'fit'. That is to say, there is no one best style - but there needs to be a proper match of style elements with the changing regulatory context. Although a proper fit should lead to better perceived organizational enforcement effectiveness, the findings in this study are somewhat ambiguous in relation to this. On the one hand, we found that perceptions about the effectiveness of 'formalism' - a style element which arguably fits the current institutional environment better-had significantly shifted from negative to positive. By itself, this would appear to support the 'fit-effectiveness presumption'. On the other hand, we did not find enforcement officials' overall perceptions of organizational enforcement effectiveness to have changed during the period. In terms of the fit thesis, it seems likely that the enforcement style element of coercion, which also increased during this period, does not 'fit', which led to offsetting effects. Taken together, these highlight both the complex nature of enforcement styles as well as issues related to the ongoing periodical assessment of organizational enforcement effectiveness by individual enforcement officials (and environmental agencies) in a highly complex and rapidly evolving task environment.

Understanding regulatory enforcement changes is important, especially in the rapidly changing contexts of emerging economies such as China. It is in these contexts that global regulatory challenges lie today and, especially, tomorrow. Such contexts demand a dynamic understanding of regulation and its enforcement that is able to capture how continuous rapid social, economic, and political change drives regulatory enforcement practices. Only a dynamic understanding of the interactions between changing institutional contexts and enforcement practices and perceptions can aid scholars and policy makers seeking improvement. The present study offers an example of empirical data collection and analysis that can help build such a dynamic view of regulatory law enforcement. The longitudinal approach used here has benefited from the concept of regulatory enforcement style elements. This concept, which has been developed from the rich body of enforcement style literature, offers an improved way to capture changes in enforcement as well as changes in the perceptions about effectiveness. It is especially useful because it allows for an empirical understanding of regulatory enforcement beyond the normative and dichotomatic deterrence and cooperation enforcement styles.

In conclusion, given the rate of environmental deterioration and its human costs in China, along with the global implications thereof, much work needs to be done. 
While academics can play an important role in this undertaking (eg, through research such as this study), the real work-like the work of the enforcement officials themselves-has to occur 'on the ground'. Regulatory compliance is dependent upon multiple actors: policy makers to promulgate sensible regulations, enforcement agencies to ensure these are implemented, the courts to sanction violators meaningfully and consistently; the communities to care enough to report and educate; and, perhaps most importantly, the enterprises themselves to accept the need to comply. Research can support these actors and help them improve compliance, but it can only do so if the research is is directly useful and is disseminated to practitioners. The conceptual framework of enforcement style elements, as well as the findings here, can help enforcement practitioners to evaluate and improve their work. It is hoped that they will be able to use this framework to develop the right mix of enforcement style elements that fits their institutional context, changing it as the context changes. In doing so, they can adopt a pragmatic view-enforcing the law as is best possible in the current circumstances, instead of chasing an unfeasible ideal.

Acknowledgements. The research for this paper is funded by the project Enforcement of Environmental Regulations in Guangzhou: A Longitudinal Study, of the Departmental General Research Fund of the Department of Management and Marketing at The Hong Kong Polytechnic University (Project Account Code: G-U234). The authors would like to thank the three anonymous reviewers for their constructive comments on the earlier two versions of the paper.

\section{References}

Alford W P, Liebman B L, 2001, "Clean air, clean processes? The struggle over air pollution law in the People's Republic of China" Hastings Law Journal $52703-748$

Ayres I, Braithwaite J, 1992 Responsive Regulation: Transcending the Deregulation Debate (Oxford University Press, New York)

Bardach E, Kagan R, 1982 Going by the Book: The Problem of Regulatory Unreasonableness (Temple University Press, Philadelphia, PA)

Becker G S, 1968, "Crime and punishment, an economic approach" Journal of Political Economy $76169-217$

Braithwaite J, Walker J, Grabosky P, 1987, "An enforcement taxonomy of regulatory agencies" Law and Policy $9323-351$

Burns J P, 1999, "Changing environmental impacts on civil service systems: the cases of China and Hong Kong", in Handbook of Comparative Public Administration in the Asia-Pacific Basin Eds H Wong, H S Chan (Marcel Dekker, New York) pp 179-219

Chan H S, Cheung K C, Lo J M K, 1993, "Environmental control in the PRC", in Public Policy in China Eds S S Nagel, M K Mills (Greenwood Press, Westport, CT) pp 63-83

Chan H S, Wong K-k, Cheung K C, Lo J M-k, 1995, "The implementation gap in environmental management in China, the case of Guangzhou, Zhengzhou, and Nanjing" Public Administration Review $55333-340$

Dasgupta S, Wheeler D, 1997 Citizen Complaints as Environmental Indicators: Evidence from China (World Bank, Washington, DC)

Dasgupta S, Laplante B, Mamingu N, Wang H, 2000, "Industrial environmental performance in China: the impact of inspections", World Bank Policy Research WP 2000

Ecological Environment and Protection, 2001, "The investment on environmental protection increased every year in the 'Ninth Five-Year Plan' period" 56 (in Chinese)

Economy E, 2004 The River Runs Black: The Environmental Challenge to China's Future (Cornell University Press, Ithaca, NY)

Ferris R J Jr, Zhang H J, 2002, "The challenges of reforming an environmental legal culture: assessing the status quo and looking at post-admission WTO challenges for the People's Republic of China" Georgetown International Environmental Law Review 14429 - 460

Frank N, Lombness M, 1988, "Gaining regulatory compliance: law enforcement and power in an interactionist perspective" Administration and Society 2071 -91

Gormley W T Jr, 1998, "Regulatory enforcement styles" Political Research Quarterly 51363 - 383

Gray W, Scholz J T, 1991, "Analyzing the equity and efficiency of OSHA enforcement" Law and Policy $13185-214$ 
Gunningham N, 1987, "Negotiated non-compliance: a case study of regulatory failure" Law and Policy $969-91$

Gunningham N, Norberry J, McKillop S (Eds), 1992 Environmental Crime (Australian Institute of Criminology, Griffith, ACT)

Hawkins K, 1984 Environment and Enforcement: Regulation and the Social Definition of Pollution (Oxford University Press, Oxford)

Ho P, 2001, "Greening without conflict? Environmentalism, NGOs and civil society in China" Development and Change $32893-921$

Ho P, Edmonds R L, 2008 China's Embedded Activism : Opportunities and Constraints of a Social Movement (Routledge, London)

Hutter B M, 1989, "Variations in regulatory enforcement styles" Law and Policy 11 153-174

Jahiel A R, 1997, "The contradictory impact of reform and environmental protection" The China Quarterly $14981-103$

Jahiel A R, 1998, "The organization of environmental protection in China" The China Quarterly $156757-787$

Kagan R A, 1994, "Regulatory enforcement", in Handbook of Regulation and Administrative Law Eds D Rosenblum, R Schwarz (Marcel Dekker, New York) pp 383-422

Kagan R A, 2000, "Introduction: comparing national styles of regulation in Japan and the United States" Law and Policy $22225-244$

Kagan R A, Scholz J T, 1984, "The criminology of the corporation and regulatory enforcement styles", in Enforcing Regulation Eds K Hawkins, J Thomas (Kluwer-Nijhoff, Boston, MA) pp $67-95$

Langbein L I, 2002, "Responsive bureaus, equity, and regulatory negotiation: an empirical view" Journal of Policy Analysis and Management 21449 - 465

Lo C W H, 1994, "Environmental management by law in China: the Guangzhou experience" The Journal of Contemporary China $639-58$

Lo C W H, Chung S S, 2003, "China's green challenges in the 21st century", in China's Challenges in the Twenty-First Century Ed. J Y S Cheng (City University of Hong Kong Press, Hong Kong) pp $719-769$

Lo C W H, Fryxell G E, 2003, "Environmental styles among environmental officials in China" Journal of Public Policy 23 81 - 115

Lo C W H, Fryxell G E, 2005, "Governmental and societal support for environmental enforcement in China: an empirical study in Guangzhou" The Journal of Development Studies $41558-589$

Lo C W H, Leung S W, 2000, "Environmental agency and public opinion in Guangzhou: the limits of a popular approach to environmental governance" The China Quarterly 163677 - 704

Lo C W H, Tang S Y, 2006, "Institutional reform, economic changes and local environmental management" Environmental Politics $15190-210$

Lo C W H, Fryxell G E, Wong W W-H, 2006, "Effective regulations with little effect? The antecedents of the perceptions of environmental officials on enforcement effectiveness in China" Environmental Management $38388-410$

Ma X, Ortolano L, 2000 Environmental Regulation in China: Institutions, Enforcement, and Compliance (Rowman and Littlefield, Totowa, NJ)

May P J, Winter S, 1999, "Regulatory enforcement and compliance: examining Danish agroenvironmental policy" Journal of Policy Analysis and Management 18 625-651

May P J, Wood R S, 2003, "At the regulatory front lines: inspectors' regulatory styles and regulatory compliance" Journal of Public Administration Research and Theory 13117 - 139

OECD, 2007 OECD Environmental Performance Reviews: China (OECD, Paris)

Palmer M, 1998, "Environmental regulation in the People's Republic of China: the face of domestic law" The China Quarterly $156788-808$

Pearl River Environment News 2006, "Constructing harmony, pursuing excellence: the first special issue on the original record of the Guangzhou classic on achieving a model city", Guangzhou Environmental Education and Publicity Centre, Guangzhou (in Chinese)

Peerenboom R, 2002 China's Long March toward Rule of Law (Cambridge University Press, Cambridge)

Reiss A Jr, 1984, "Selecting strategies of social control over organizational life", in Enforcing Regulation Eds K Hawkins, J Thomas (Kluwer-Nijhoff, Boston, MA)

Richardson G, Ogus A, Burrows P, 1983 Policing Pollution: A Study of Regulation and Enforcement (Oxford University Press, New York)

Scholz J T, 1984, "Cooperation, deterrence and the ecology of regulatory enforcement" Law and Society Review $18601-646$ 
Scholz J T, Gray W B, 1997, “ Can government facilitate cooperation? An informational model of OSHA enforcement” American Journal of Political Science 41 693-717

Scholz J T, Tombly T J, Headrick B, 1991, "Street level political controls over federal bureaucracy" American Political Science Review $85829-850$

Sinkule B, Ortolano L, 1995 Implementing Environmental Policy in China (Praeger, New York)

Stalley P, Yang D N, 2006, "An emerging environmental movement in China?" The China Quarterly $186333-356$

State Environmental Protection Administration, 2000 - 2006 China Environment Statistical Report 2000 - 2006 (Zhongguo Huanjing Kexue Chubanshe, Beijing) (in Chinese)

Swanson K E, Kuhn R G, Wei Xu, 2001, "Environmental policy implementation in rural China: a case study of Yuhang, Zhejiang" Environmental Management 27481 - 491

Tang S-Y, Lo C W H, Cheung K-C, Lo J M-K, 1997, "Institutional constraints on environmental management in urban China: environmental impact assessment in Guangzhou and Shanghai" China Quarterly $152863-874$

Tang S Y, Lo C W H, Fryxell G E, 2003, "Enforcement styles, organizational commitment, and enforcement effectiveness: an empirical study of local environmental protection officials in urban China" Environment and Planning A 3575 -94

Tilt B, 2007, "The political ecology of pollution enforcement in China: a case of Sichuan's rural industrial sector" China Quarterly 192915 -933

Van Rooij B, 2002, "Implementing Chinese environmental law through enforcement, the shiwu xiao and shuangge dabiao campaigns", in The Implementation of Law in the People's Republic of China Eds J Chen, Y Li, J M Otto (Kluwer Law International, The Hague) pp 149 - 178

Van Rooij B, 2003, "Environmental law enforcement in Sichuan: organization and procedure in comparative perspective" China Information 17 36-65

Van Rooij B, 2006 Regulating Land and Pollution in China, Lawmaking, Compliance, and Enforcement; Theory and Cases (Leiden University Press, Leiden)

Wang H, Wheeler D, 2000, "Endogenous enforcement and effectiveness of China's pollution levy system", World Bank Policy Research Working Paper

Wang H, Mamingi N, Laplante B, Dasgupta S, 2003, "Incomplete enforcement of pollution regulation: bargaining power of Chinese factories" Environmental and Resource Economics $24245-262$

Warwick M, Ortolano L, 2007, "Benefits and costs of Shanghai's environmental citizen complaints system" China Information XXI 237-269

Wood D, 1988, "Principals, bureaucrats, and responsiveness in clean air enforcement" American Political Science Review 82213 - 237

Wood D, Waterman R W, 1991, "The dynamics of political control of the bureaucracy" American Political Science Review $\mathbf{8 5} 801$ - 828

Yang G, 2005, "Environmental NGOs and institutional dynamics in China" China Quarterly $18146-66$

Zhang L, 2002 Ecologizing Industrialization in Chinese Small Towns $\mathrm{PhD}$ thesis, Wageningen University, Wageningen 
Conditions of use. This article may be downloaded from the E\&P website for personal research by members of subscribing organisations. This PDF may not be placed on any website (or other online distribution system) without permission of the publisher. 